\title{
Plasma fat-soluble vitamin and carotenoid concentrations after plant sterol and plant stanol consumption: a meta-analysis of randomized controlled trials
}

\author{
Sabine Baumgartner ${ }^{1} \cdot{\text { Rouyanne T. } \operatorname{Ras}^{2} \cdot \text { Elke A. Trautwein }}^{2} \cdot$ Ronald P. Mensink $^{1} \cdot$ \\ Jogchum Plat ${ }^{1}$
}

Received: 29 April 2016 / Accepted: 29 July 2016 / Published online: 3 September 2016

(c) The Author(s) 2016. This article is published with open access at Springerlink.com

\begin{abstract}
Purpose Plant sterols and stanols interfere with intestinal cholesterol absorption, and it has been questioned whether absorption and plasma concentrations of fat-soluble vitamins and carotenoids are also affected. We conducted a meta-analysis to assess the effects of plant sterol and stanol consumption on plasma fat-soluble vitamin and carotenoid concentrations.

Methods Forty-one randomized controlled trials involving 3306 subjects were included. Weighted absolute and relative changes of non-standardized and total cholesterol (TC)-standardized values (expressed as summary estimates and $95 \%$ CIs) were calculated for three fat-soluble vitamins ( $\alpha$ - and $\gamma$-tocopherol, retinol and vitamin D) and six carotenoids ( $\beta$-carotene, $\alpha$-carotene, lycopene, lutein, zeaxanthin and $\beta$-cryptoxanthin) using a random effects model. Heterogeneity was assessed using predefined subject and treatment characteristics.

Results Average plant sterol or stanol intake was $2.5 \mathrm{~g} / \mathrm{d}$. Relative non-standardized and TC-standardized concentrations of $\beta$-carotene decreased by, respectively, $-16.3 \%$ (95\% CI
\end{abstract}

S. Baumgartner and R. T. Ras have contributed equally to this work.

Electronic supplementary material The online version of this article (doi:10.1007/s00394-016-1289-7) contains supplementary material, which is available to authorized users.

Sabine Baumgartner

sabine.baumgartner@maastrichtuniversity.nl

1 Department of Human Biology, NUTRIM School of Nutrition and Translational Research in Metabolism, Maastricht University, PO Box 616, 6200 MD Maastricht, The Netherlands

2 Unilever R\&D Vlaardingen, Vlaardingen, The Netherlands
$-18.3 ;-14.3)$ and $-10.1 \%(-12.3 ;-8.0), \alpha$-carotene by $-14.4 \%(-17.5 ; 11.3)$ and $-7.8 \%(-11.3 ;-4.3)$, and lycopene by $-12.3 \%(-14.6 ;-10.1)$ and $-6.3 \%(-8.6 ;-4.0)$. Lutein concentrations decreased by $-7.4 \%(-10.1 ;-4.8)$, while TC-standardized concentrations were not changed. For zeaxanthin, these values were $-12.9 \%(-18.9 ;-6.8)$ and $-7.7 \%(-13.8 ;-1.7)$ and for $\beta$-cryptoxanthin $-10.6 \%$ $(-14.3 ;-6.9)$ and $-4.8 \%(-8.7 ;-0.9)$. Non-standardized $\alpha$-tocopherol concentrations decreased by $-7.1 \%(-8.0$; $-6.2)$ and $\gamma$-tocopherol by $-6.9 \%(-9.8 ;-3.9)$, while TCstandardized tocopherol concentrations were not changed. Non-standardized retinol and vitamin D concentrations were not affected. Results were not affected by baseline concentrations, dose, duration and type of plant sterols/stanols, except for significant effects of duration ( $\leq 4 \mathrm{vs.}>4$ weeks) on TCstandardized lutein concentrations (1.0 vs. $-5.6 \%)$ and type of plant sterol/stanol on TC-standardized $\beta$-carotene concentrations ( -8.9 vs. $-14.2 \%)$.

Conclusions Plant sterol and stanol intake lowers TCstandardized hydrocarbon carotenoid concentrations, differently affects TC-standardized oxygenated carotenoid concentrations, but does not affect TC-standardized tocopherol concentrations or absolute retinol and vitamin $\mathrm{D}$ concentrations. Observed concentrations remained within normal ranges.

Keywords Plant sterols · Plant stanols · Cholesterol · Hydrocarbon carotenoids - Oxygenated carotenoids · Fatsoluble vitamins

\section{Introduction}

Numerous studies have shown that consuming plant sterolor plant stanol-enriched foods (0.6-3.3 g sterols or stanols/ 
day) lowers plasma or serum low-density lipoprotein cholesterol (LDL-C) concentrations by 6-12\% [1-3]. Since plant sterols and plant stanols interfere with intestinal cholesterol absorption and consequently affect whole-body lipid and lipoprotein metabolism [4], questions have been raised whether plasma fat-soluble vitamin and carotenoid concentrations are also affected by plant sterol and stanol consumption. A reduction in plasma fat-soluble vitamin and carotenoid concentrations may be undesirable, since in prospective cohort studies lower concentrations have been associated with an increased risk of several chronic diseases, such as cardiovascular diseases (CVDs), cancer and age-related macular degeneration (AMD) [5-7], although evidence from randomized controlled trials is lacking $[8,9]$.

Already in 2003, Katan et al. [10] performed a metaanalysis including 18 studies and showed significant reductions in circulating $\alpha$-tocopherol, $\alpha$-carotene, $\beta$-carotene and lycopene concentrations after plant sterol and stanol ester consumption. Concentrations of the fat-soluble vitamins retinol and vitamin D were not affected. However, when concentrations were standardized for serum total cholesterol (TC) concentrations, there were no longer decreases in $\alpha$-tocopherol, $\alpha$-carotene and lycopene concentrations, while $\beta$-carotene concentrations remained significantly reduced with a mean reduction of $12 \%$. This implies that at least for some of the vitamins and carotenoids decreases are related to the reduction in the number of circulating lipoproteins, the carriers of the fat-soluble tocopherols and carotenoids. However, it has also been suggested that plant sterols and stanols reduce the incorporation of the more lipophilic hydrocarbon carotenoids (i.e., $\beta$-carotene, $\alpha$-carotene and lycopene) into the micelles to a greater extent than those of the less lipophilic oxygenated carotenoids (lutein, zeaxanthin and $\beta$-cryptoxanthin) and tocopherols [11]. Finally, plant sterol and plant stanol consumption might not affect vitamins that require a specific transporter instead of the lipoprotein-mediated transport route, such as retinol and vitamin $\mathrm{D}$.

Recently, Fardet et al. [12] have summarized the effects of plant sterols and plant stanols on fat-soluble vitamin and carotenoid concentrations. They calculated median relative changes (standardized and non-standardized) in $\alpha$-tocopherol, $\gamma$-tocopherol, $\alpha$-carotene, $\beta$-carotene and $\beta$-cryptoxanthin concentrations. However, results seem biased as only studies were included that reported significant reductions in plasma fat-soluble vitamin and carotenoid concentrations. In addition, a detailed description of the systematic approach to review the available literature was lacking. Therefore, to provide an up-to-date quantitated overview on the effects of plant sterol or plant stanol consumption on plasma fat-soluble vitamin and carotenoid concentrations, we performed a meta-analysis of randomized controlled trials (RCTs). For this, absolute and relative changes were estimated for three fat-soluble vitamin $(\alpha$ - and $\gamma$-tocopherol, retinol and vitamin $D)$ and six carotenoid ( $\beta$-carotene, $\alpha$-carotene, lycopene, lutein, zeaxanthin and $\beta$-cryptoxanthin) concentrations after plant sterol or plant stanol consumption. Furthermore, potential sources of heterogeneity between studies were assessed by investigating the impact of predefined subject and treatment characteristics on changes in plasma fat-soluble vitamin and carotenoid concentrations.

\section{Methods}

\section{Search strategy}

Potentially relevant studies were retrieved by a systematic search of five databases (Medline, Embase, the Cochrane Library, Cab abstracts and Food, Science and Technology abstracts) in December 2014. A search strategy was developed including the Medical Subject Heading 'phytosterols' and the following search terms: (plant sterol* or phytosterol* or sitosterol* or campesterol* or stigmasterol* or brassicasterol* or plant stanol* or sitostanol* or campestanol*) and (vitamin* or carotene* or carotenoid* or tocotrienol* or tocopherol* or alpha-carotene* or beta-carotene* or lycopene* or lutein* or zeaxanthin* or retinol* or calciferol*), limited to humans without any restriction on language. Throughout this paper, the term 'plasma' is used, irrespective whether plasma or serum concentrations were reported in the different studies.

\section{Selection of studies}

Human intervention studies were considered eligible if effects of plant sterol or plant stanol consumption on plasma fat-soluble vitamin or carotenoid concentrations were reported. In the first selection round, titles and abstracts were screened and studies were selected if they met the following inclusion criteria: (1) RCT in humans (studies with children were allowed), (2) oral intake of plant sterol- or plant stanol-enriched foods or supplements, (3) measurement of plasma fat-soluble vitamins or carotenoids, (4) no co-intervention next to the plant sterol or plant stanol intervention, (5) no studies in phytosterolemic patients, (6) duration of at least 2 weeks and (7) no duplicates. For the second selection round, full publications were read to assess their eligibility. Studies were excluded when they lacked a control group or were not randomized, when an intentional co-intervention (e.g., extra vitamins) was given that could not be separated from the effects of the plant sterol or plant stanol intervention or when plasma fat-soluble vitamin or carotenoid concentrations were not reported. Studies evaluating the effects of ferulated plant 
sterols (as in shea nut oil) were not included, since they are not commonly used in currently commercially available plant sterol- and stanol-enriched foods and there is no consensus on their cholesterol-lowering effects [13, 14]. When inconclusive, the eligibility of studies was discussed among authors until consensus was reached.

\section{Data extraction and transformation}

Data were collected using a database that included (1) publication characteristics (reference number, first author and year of publication), (2) study characteristics (parallel or crossover design, sample size and study duration), (3) subject characteristics (health status, mean age, mean BMI and gender distribution), (4) treatment characteristics (use of plant sterols or plant stanols, dose of plant sterols or plant stanols and food format), (5) measurement characteristics (serum or plasma) and (6) outcome variables [plasma and serum concentrations of $\alpha$-carotene, $\beta$-carotene, $\alpha$-tocopherol, $\gamma$-tocopherol, lutein, zeaxanthin, $\beta$-cryptoxanthin, lycopene, vitamin $\mathrm{D}$, retinol, TC, LDL-C, high-density lipoprotein cholesterol (HDL-C) and triacylglycerols (TAG)].

For all outcome variables, mean concentrations and accompanying variance measures were extracted at baseline and at the end of the intervention. In the circulation, tocopherols and carotenoids are transported by lipoprotein particles and therefore often standardized for serum cholesterol concentrations. Since vitamin D and retinol are not transported by lipoproteins, they were solely expressed as non-standardized concentrations. To unify the use of all cholesterol-standardized tocopherol and carotenoid concentrations, absolute TC data were extracted and TCstandardized tocopherol and carotenoid concentrations were calculated by dividing the absolute tocopherol/carotenoid concentrations at baseline and at end of intervention by the respective TC concentrations. Original authors were contacted for non-standardized tocopherol and carotenoid concentrations if only cholesterol-standardized levels were reported [15-19].

Cholesterol data (TC, LDL-C and HDL-C) and TAG data expressed in $\mathrm{mg} / \mathrm{dL}$ were converted into $\mathrm{mmol} / \mathrm{L}$ by using their molecular weights (386.7 and $885.7 \mathrm{~g} / \mathrm{mol}$, respectively). In case fat-soluble vitamin or carotenoid concentrations were expressed in $\mathrm{ng} / \mathrm{mL}, \mathrm{ng} / \mathrm{dL}, \mu \mathrm{g} / \mathrm{mL}, \mu \mathrm{g} /$ $\mathrm{dL}, \mu \mathrm{g} / \mathrm{L}, \mathrm{mg} / \mathrm{dL}, \mathrm{mg} / \mathrm{L}, \mathrm{g} / \mathrm{mL}$, these data were also transformed based on their molecular weights to derive concentrations in $\mu \mathrm{mol} / \mathrm{L}$ or $\mathrm{nmol} / \mathrm{L}(\mathrm{g} / \mathrm{mol}$ for $\alpha$ - and $\beta$-carotene: 536.9, $\alpha$-tocopherol: 430.7, $\gamma$-tocopherol: 416.7, lutein and zeaxanthin: $568.9 ; \beta$-cryptoxanthin: 552.9 , lycopene: 536.9, retinol: 286.5 and vitamin D: 400.6). These transformations were done for means and for SEs or SDs.

Placebo-adjusted absolute and relative changes with accompanying SEs were calculated for $\alpha$-carotene, $\beta$-carotene, $\alpha$-tocopherol, $\gamma$-tocopherol, lutein, zeaxanthin, $\beta$-cryptoxanthin, lycopene, vitamin $\mathrm{D}$, retinol, TC, LDLC, HDL-C and TAG for each study (when data were available). For parallel studies, absolute and relative changes (with accompanying SEs) were calculated based on average concentrations and variance measures at baseline and at end of intervention of treatment and control groups. For crossover studies, absolute and relative changes were calculated based on concentrations at end of intervention of treatment and control periods. In case it was not possible to calculate placebo-adjusted changes and SEs, these data were used as reported in the papers [16, 20-25]. Data expressed as median (minimum, maximum) values were transformed to means \pm SDs using the method of Wan et al. [26, 27] and data displayed in graphs were extracted using ScanIt version 1.0 [23, 28-31]. To derive SE from $95 \%$ CI $[13,14]$ or from an effect estimate and $P$ value [20], equations were used as described by the Cochrane handbook for systematic reviews of interventions [32]. The Friedewald equation [33] was used for one study [34] to estimate the TC concentration based on the reported concentrations of LDL-C, HDL-C and TG. In case only TC-standardized data were available, these data were added in SAS [23].

\section{Statistical analysis}

For each outcome parameter, a weighted net effect (expressed as summary estimate and $95 \% \mathrm{CI}$ ) was calculated using a random effects model and the inverse of the within-study variance $\left(1 / \mathrm{SE}^{2}\right)$ was used as weighing factor [35]. These effects were calculated for baseline concentrations, end-of-intervention concentrations, absolute and relative changes of non-standardized and TC-standardized values. For interpretation of the data, the various outcome parameters were clustered in hydrocarbon or oxygenated carotenoids, in fat-soluble vitamins or plasma lipids. Forest plots were made for relative changes in representatives of the three fat-soluble vitamin/carotenoid categories ( $\beta$-carotene representing the hydrocarbon carotenoids, lutein the oxygenated carotenoids and $\alpha$-tocopherol the tocopherols).

Funnel plots were created to visualize the likeliness of heterogeneity (in case many effect sizes fall outside the confidence limits) and publication bias (in case of asymmetry). Heterogeneity was assessed using Cochran's $Q$ test $(P<0.1$ indicates significant heterogeneity $)$ and quantified by $\mathrm{I}^{2}$, which indicates the percentage of variability in effect estimate that is due to heterogeneity rather than sampling error [35, 36]. Publication bias was evaluated by Egger's weighted regression test where the absence of publication bias is reflected by an intercept close to $0(P \geq 0.05)$ [37].

Subgroup analyses were performed for $\beta$-carotene, lutein and $\alpha$-tocopherol as representatives of the 
hydrocarbon carotenoids, oxygenated carotenoids and tocopherols to evaluate whether TC-standardized absolute and relative changes were influenced by predefined subject characteristics (i.e., baseline concentrations of $\beta$-carotene, lutein and $\alpha$-tocopherol) or treatment characteristic (i.e., use of plant sterols or plant stanols, dose of plant sterols or plant stanols and duration of intervention). Subgroup analyses were also performed for effects on TC. Subgroups were defined using the median baseline concentrations and the median duration (4 weeks) as cut-offs. For the dose categories, we used 1.6, 2.0, 3.0 and $9.0 \mathrm{~g} / \mathrm{d}$ as cut-offs allowing a more or less equal distribution of studies across the four dose categories.

Results were considered to be statistically significant if $P<0.05$ based on two-sided testing. All statistical analyses were performed using SAS version 9.4 (SAS institute Inc., Cary, NC, USA). Forest plots were created using STATA version 12.1 (STATA Corporation, College Station, TX, USA). This meta-analysis adheres to the PRISMA statement guidelines for reporting in systematic reviews and meta-analyses.

\section{Results}

\section{Overview of included studies}

The systematic search retrieved 1084 potentially relevant papers, and after two selection rounds, 41 RCTs were included in the meta-analysis. A flowchart of the study selection process is presented in Fig. 1.
Of the 41 included studies (Online Supplemental Material Tables 1 and 2), 23 were conducted as a parallel study [15-17, 19, 21-26, 28-31, 34, 38-45] and 18 studies had a crossover design [13, 14, 18, 20, 46-59]. In total, 3306 subjects participated with an average age of 47.6 years (range 10.5-61.8 years) and an average BMI of $25.1 \mathrm{~kg} / \mathrm{m}^{2}$ (range $\left.19.0-28.3 \mathrm{~kg} / \mathrm{m}^{2}\right)$. The median study duration was 28 days (range 21-364 days) with an average dose of $2.5 \mathrm{~g} / \mathrm{d}$ (range $0.45-9.0 \mathrm{~g} / \mathrm{d}$ ), and $80 \%$ of the studies were performed with esterified plant sterols or plant stanols.

\section{Plasma fat-soluble vitamin/carotenoid outcomes}

The weighted effects of plant sterol or plant stanol consumption on plasma fat-soluble vitamin and carotenoid concentrations are presented in Table 1. Non-standardized and TC-standardized hydrocarbon carotenoid concentrations, i.e., lycopene, $\alpha$-carotene and $\beta$-carotene, were significantly $(P<0.0001)$ lowered after consumption of plant sterol- or plant stanol-enriched foods. $\beta$-Carotene concentrations decreased on average by $0.08 \mu \mathrm{mol} / \mathrm{L}$ $(-16.3 \% ;-10.1 \%$ when TC-standardized), $\alpha$-carotene concentrations by $0.02 \mu \mathrm{mol} / \mathrm{L} \quad(-14.4 \% ;-7.8 \%$ when TC-standardized) and lycopene concentrations by $-0.04 \mu \mathrm{mol} / \mathrm{L}(-12.3 \% ;-6.3 \%$ when TC-standardized). For the oxygenated carotenoids, i.e., lutein, zeaxanthin and $\beta$-cryptoxanthin, non-standardized concentrations were significantly $(P<0.0001)$ lowered, while changes in TCstandardized concentrations showed less conclusive results. Lutein concentrations decreased on average by $0.02 \mu \mathrm{mol} / \mathrm{L}$ $(-7.4 \%)$, while the TC-standardized concentrations in
Fig. 1 Flowchart study selection process. The literature search retrieves 1084 potentially relevant papers, 1009 are excluded after screening titles and abstracts, 75 articles are reviewed in full and 41 randomized controlled trials (RCTs) are included in the meta-analysis

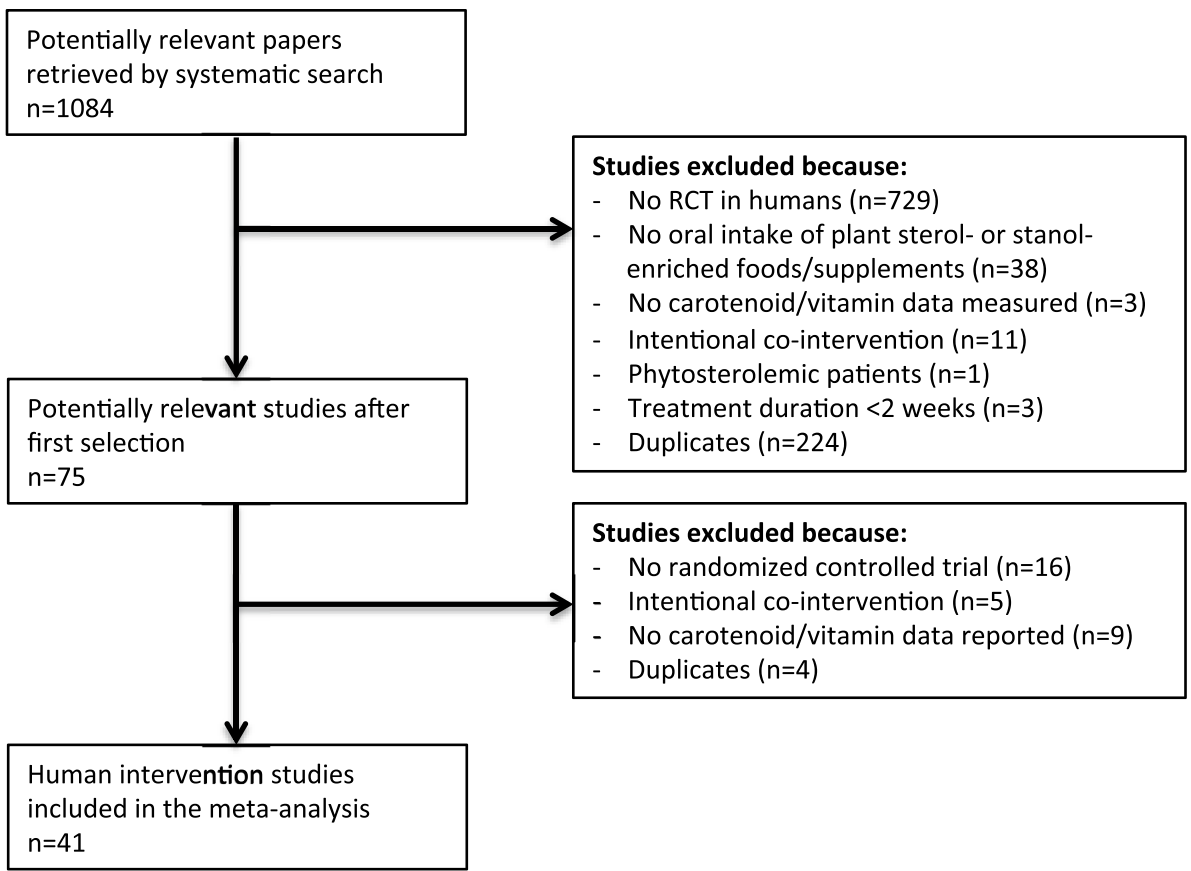




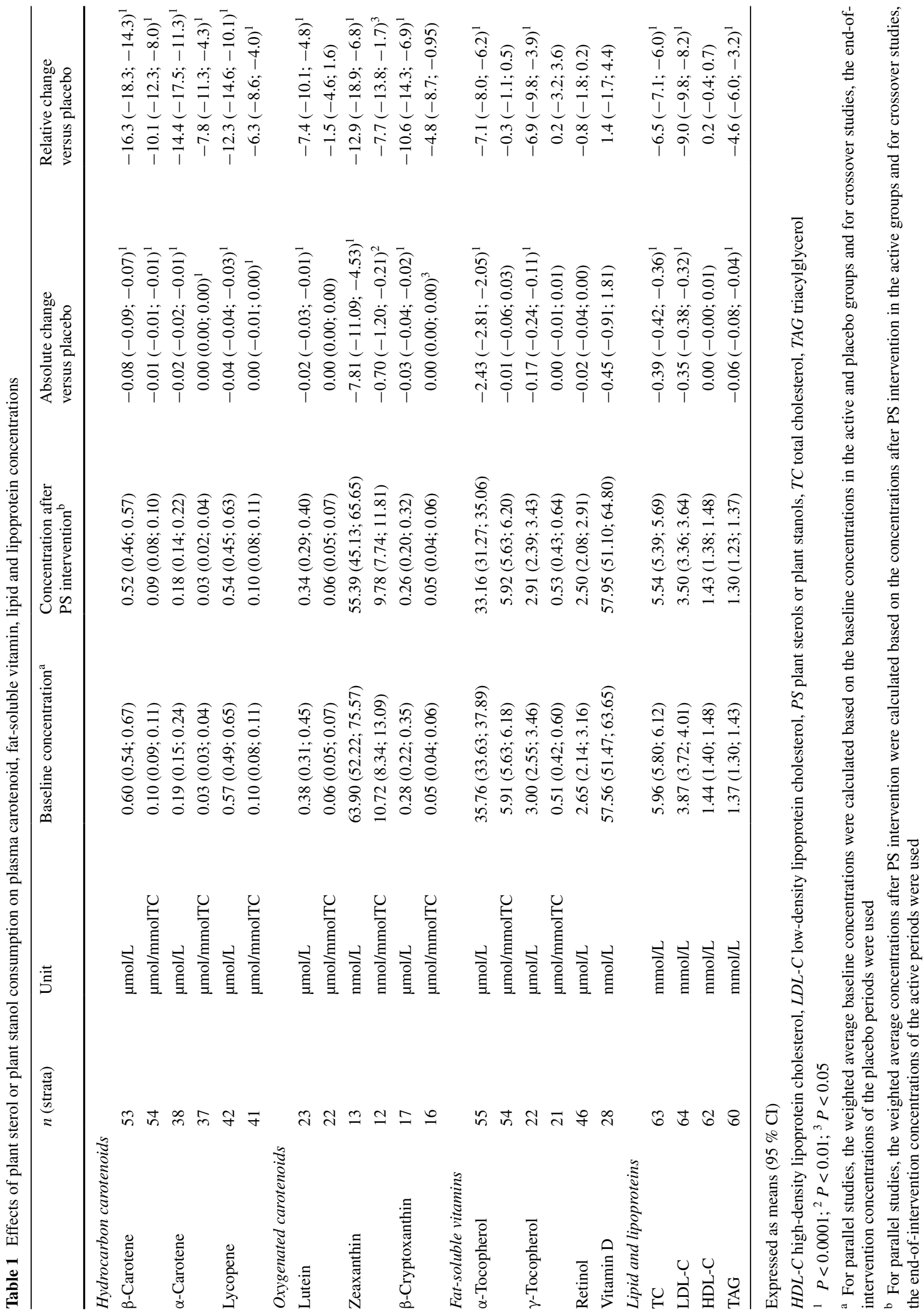




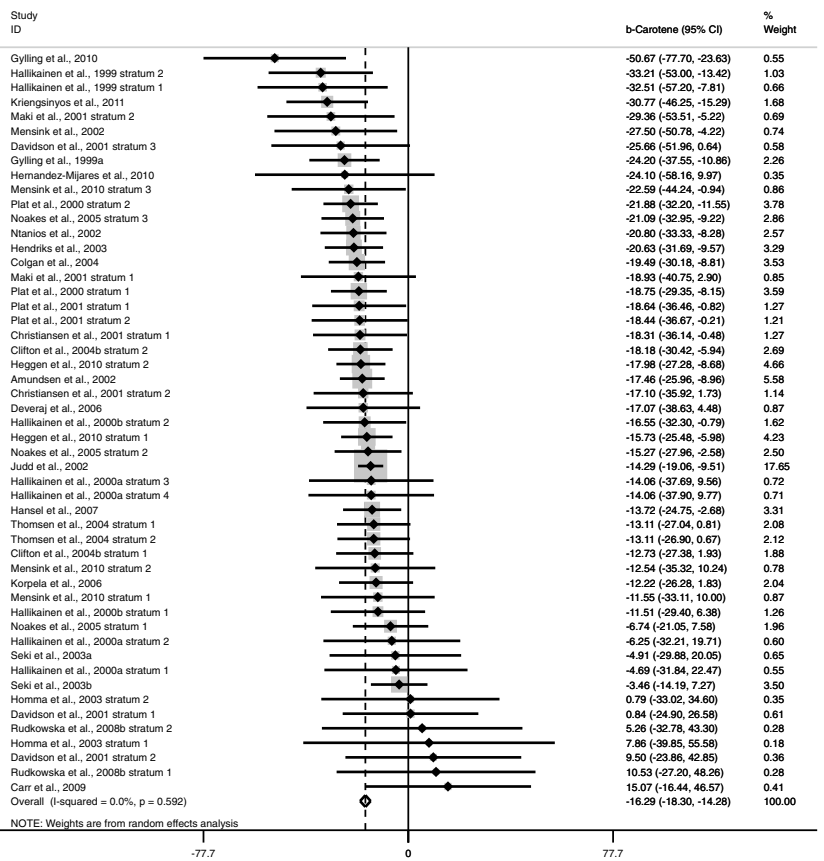

Fig. 2 Forest plot relative change (expressed as summary estimates and $95 \%$ CIs) in non-standardized (left panel) and TC-standardized (right panel) plasma $\beta$-carotene concentrations. The solid squares represent the weight of individual study arms, and the pooled effect

lutein were not significantly changed $(-1.5 \%)$ after plant sterol or plant stanol consumption. Non-standardized zeaxanthin concentrations decreased on average by $7.81 \mathrm{nmol} / \mathrm{L}$ $(-12.9 \% ;-7.7 \%$ when TC-standardized $(P<0.05))$ and $\beta$-cryptoxanthin decreased by $-0.03 \mu \mathrm{mol} / \mathrm{L}[-10.6 \%$; $-4.8 \%$ when TC-standardized $(P<0.05)]$. Non-standardized tocopherol concentrations significantly $(P<0.0001)$ decreased after plant sterol or plant stanol consumption ( $\alpha$-tocopherol on average by $2.43 \mu \mathrm{mol} / \mathrm{L}(-7.1 \%)$ and $\gamma$-tocopherol by $0.17 \mu \mathrm{mol} / \mathrm{L}(-6.9 \%)$. However, when standardized for TC concentrations, $\alpha$ - and $\gamma$-tocopherol concentrations were no longer changed after plant sterol or plant stanol consumption ( -0.3 and $0.2 \%$, respectively; $P>0.05)$. Concentrations of retinol and vitamin D were not changed after plant sterol or plant stanol consumption $(-0.8$ and $1.4 \%$, respectively; $P>0.05)$.

TC concentrations were significantly $(P<0.0001)$ decreased on average by $0.39 \mathrm{mmol} / \mathrm{L}(-6.5 \%)$ and LDL-C concentrations by $0.35 \mathrm{mmol} / \mathrm{L}(-9.0 \%)$. HDL-C concentrations did not change after plant sterol or plant stanol consumption $(0.2 \%)$, while TAG concentrations were significantly $(P<0.0001)$ decreased by $0.06 \mathrm{mmol} / \mathrm{L}$ $(-4.6 \%)$ (Table 1$)$.

Figures 2, 3 and 4 show forest plots of the relative nonstandardized and TC-standardized changes for $\beta$-carotene, lutein and $\alpha$-tocopherol. Funnel plots for the relative nonstandardized and TC-standardized changes in $\beta$-carotene,

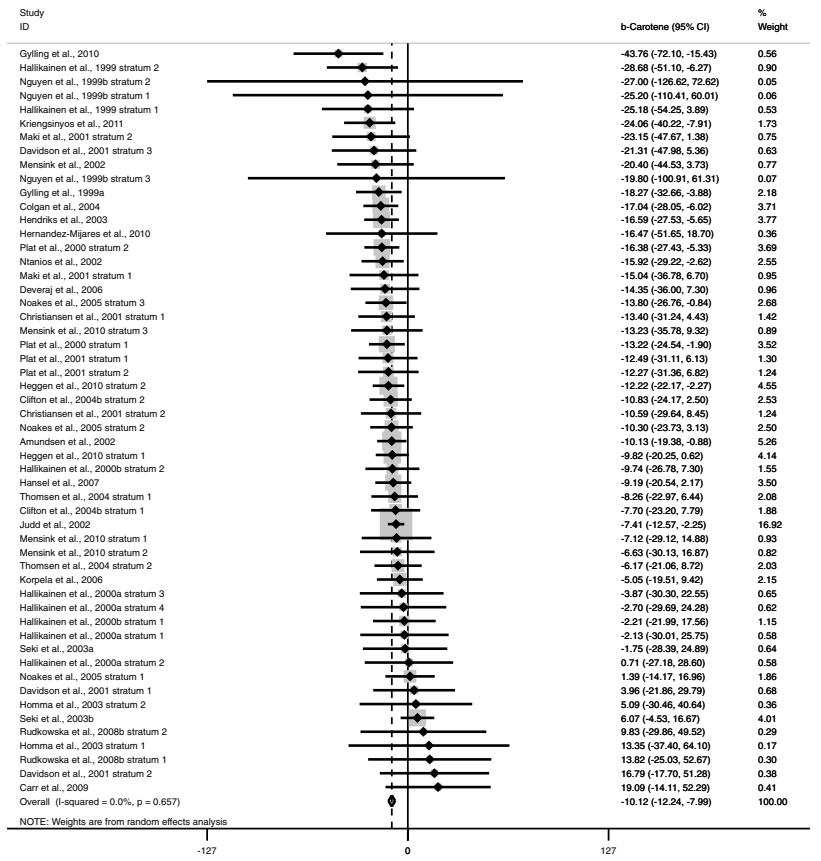

estimate is represented as a diamond. Heterogeneity is assessed using Cochran's $Q$ test $(P<0.1$ indicates significant heterogeneity) and quantified by $\mathrm{I}^{2}$, where $>50 \%$ indicates substantial heterogeneity

lutein and $\alpha$-tocopherol are shown in Online Supplemental Material Figs. 1-3. Visual inspection and calculation of $\mathrm{I}^{2}$ statistics $(P<0.05)$ indicated substantial heterogeneity in the relative non-standardized changes of $\alpha$-tocopherol. Heterogeneity was also present for relative non-standardized changes of zeaxanthin and lycopene and for the relative TC-standardized changes of $\alpha$-carotene and zeaxanthin (data not shown). Publication bias seemed only present for $\alpha$-carotene (Egger test: $P$ (intercept) $<0.05$; studies reporting small decreases in plasma changes seemed lacking, data not shown).

\section{Covariate analyses}

Table 2 provides an overview of the covariate analyses for the TC-standardized changes in $\beta$-carotene, lutein, $\alpha$-tocopherol ( $\beta$-carotene representing the hydrocarbon carotenoids, lutein the oxygenated carotenoids and $\alpha$-tocopherol the tocopherols) and for TC concentrations. Overall, baseline concentrations did not have a significant impact on the observed changes after plant sterol or plant stanol consumption. Only some trends were observed implying larger absolute reductions in $\beta$-carotene and larger absolute and relative reductions in $\alpha$-tocopherol with higher baseline values. Furthermore, the plant sterol or plant stanol dose did not significantly affect TC-standardized absolute or relative changes in $\beta$-carotene, lutein 


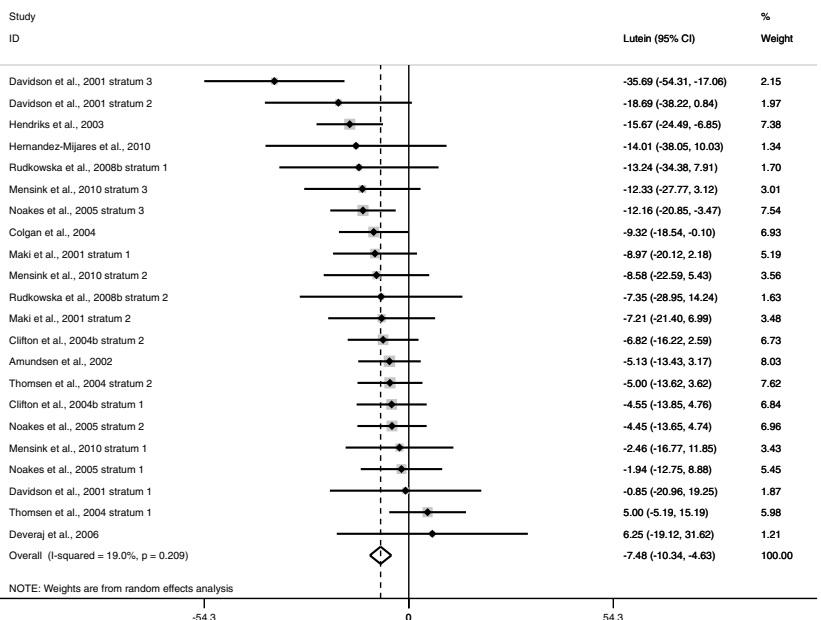

Fig. 3 Forest plot relative change (expressed as summary estimates and $95 \%$ CIs) in non-standardized (left panel) and TC-standardized (right panel) plasma lutein concentrations. The solid squares represent the weight of individual study arms, and the pooled effect esti-

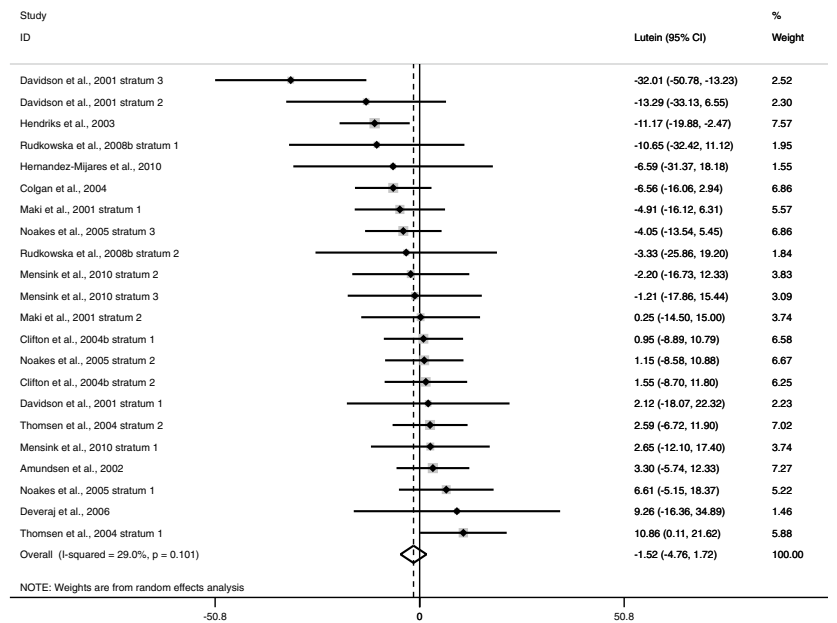

mate is represented as a diamond. Heterogeneity is assessed using Cochran's $Q$ test $(P<0.1$ indicates significant heterogeneity) and quantified by $\mathrm{I}^{2}$, where $>50 \%$ indicates substantial heterogeneity

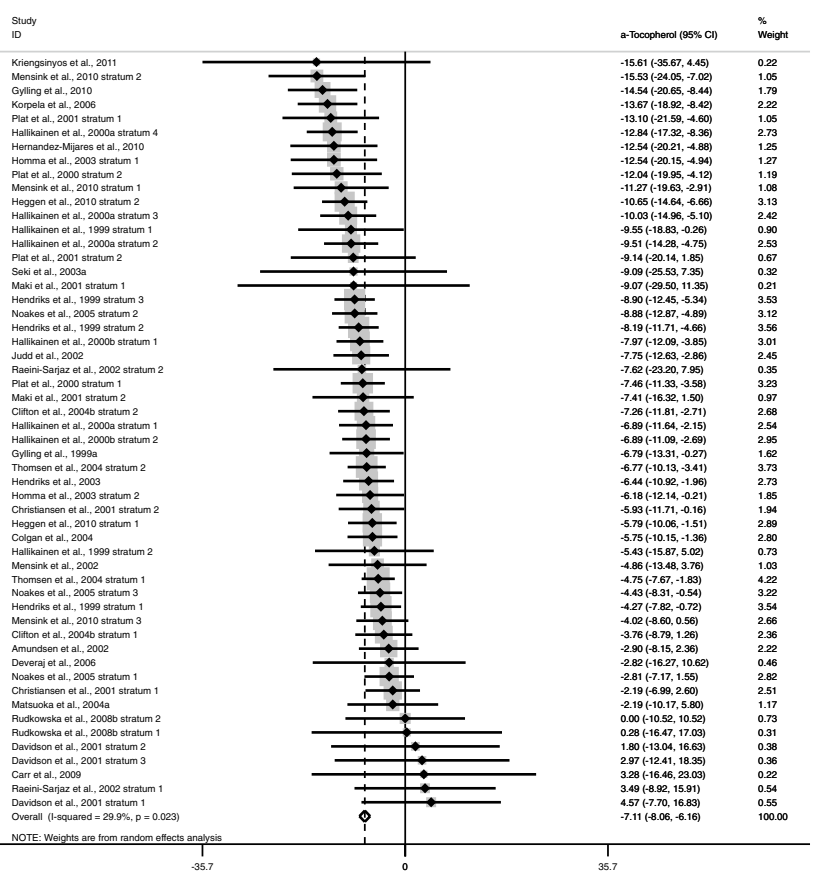

Fig. 4 Forest plot relative change (expressed as summary estimates and $95 \%$ CIs) in non-standardized (left panel) and TC-standardized (right panel) plasma $\alpha$-tocopherol concentrations. The solid squares represent the weight of individual study arms, and the pooled effect

and $\alpha$-tocopherol. Only study duration ( $\leq 4$ vs. $>4$ weeks) resulted in larger TC-standardized absolute and relative reductions in lutein $(0.000$ vs. $-0.002 \mu \mathrm{mol} / \mathrm{mmol} \mathrm{TC}$ and 1.0 vs. $-5.6 \%$, respectively), whereas only a trend for such effect was observed for $\beta$-carotene. Consumption of plant stanols seemed to have a stronger effect on

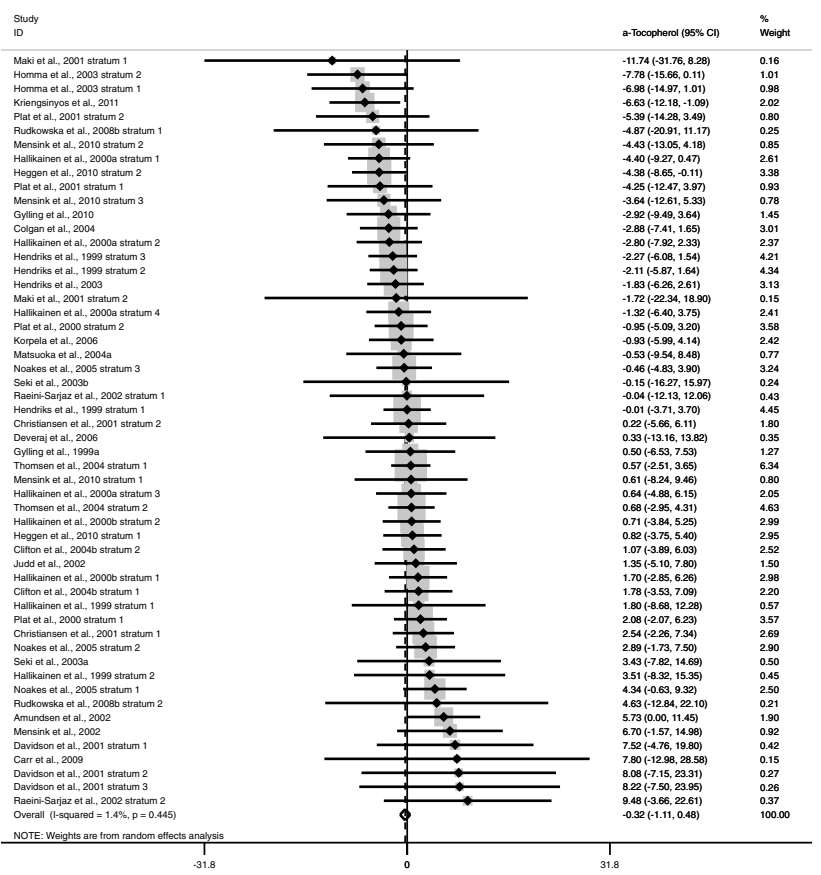

estimate is represented as a diamond. Heterogeneity is assessed using Cochran's $Q$ test $(P<0.1$ indicates significant heterogeneity) and quantified by $\mathrm{I}^{2}$, where $>50 \%$ indicates substantial heterogeneity

lowering relative TC-standardized $\beta$-carotene concentrations than plant sterols ( -14.2 vs. $-8.9 \%$, respectively), while changes in $\alpha$-tocopherol concentrations showed a trend toward larger reductions after plant stanol vs. sterol consumption. Changes in TC concentrations were also larger after consumption of plant stanols vs. plant sterols 


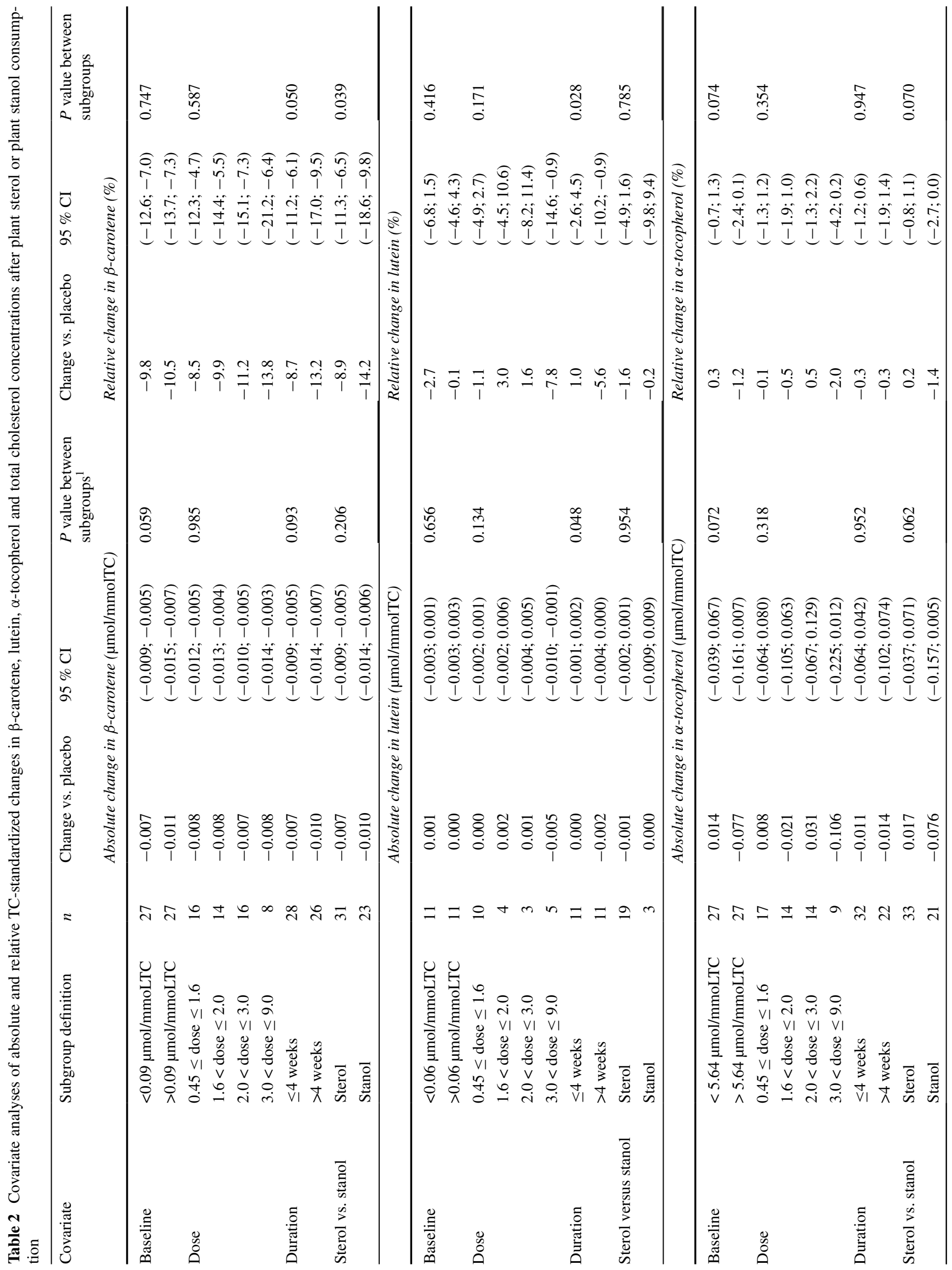




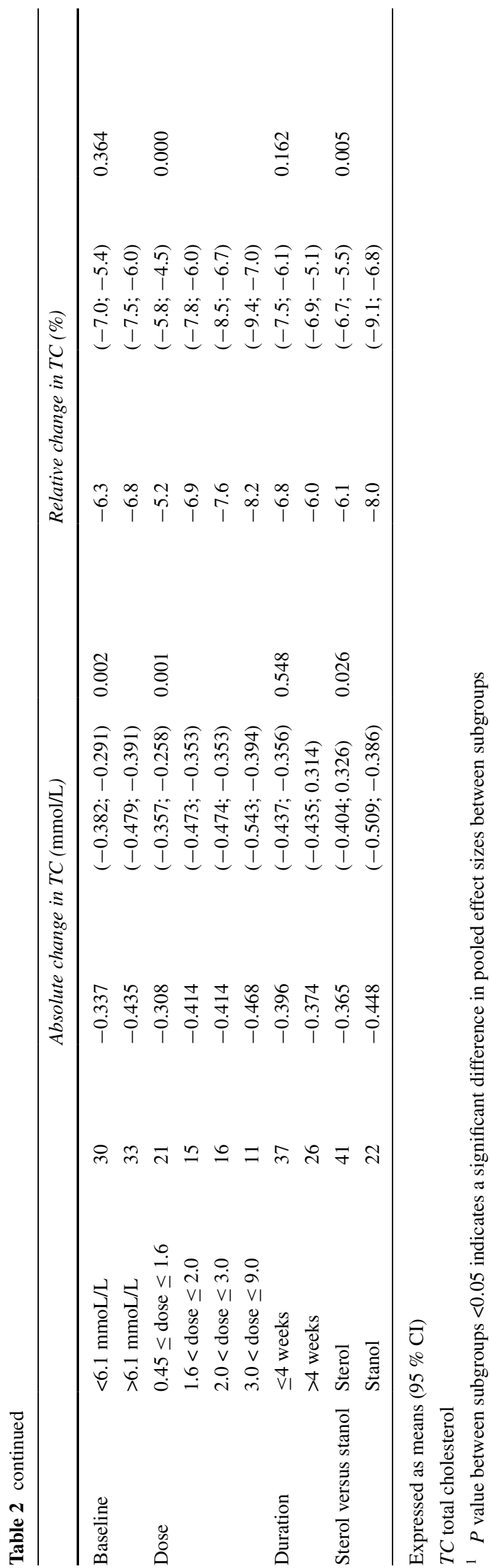

( -8.0 vs. $-6.1 \%$, respectively), which is probably related to a higher dose in the plant stanol compared to the plant sterol studies ( 3.2 vs. $2.1 \mathrm{~g} / \mathrm{d}$ ). In addition, changes in TC concentrations after plant sterol or plant stanol consumption were significantly affected by baseline concentrations (only absolute TC changes) and by the dose of plant sterol or plant stanol intake.

\section{Discussion}

Although there is general consensus about the serum cholesterol-lowering efficacy of consuming foods enriched with plant sterols and stanols, there is an ongoing discussion around the potential effects of these ingredients on plasma fat-soluble vitamin and carotenoid concentrations. Therefore, we here present the first extensive systematic review and meta-analysis to estimate the effects of plant sterol and plant stanol consumption on plasma fat-soluble vitamin and carotenoid concentrations. We observed a decrease in non-standardized (hydrocarbon and oxygenated) carotenoids and in tocopherol concentrations, but not in vitamin D and retinol concentrations. TC-standardized concentrations remained significantly decreased for all individual hydrocarbon carotenoids, while the oxygenated carotenoid concentrations were differently affected and TC-standardized tocopherol concentrations were not changed after plant sterol and plant stanol consumption.

In an earlier less extensive review from 2003 by Katan et al. [10] including eighteen studies, a reduction in TCstandardized $\beta$-carotene was found, while TC-standardized concentrations of $\alpha$-carotene, lycopene, $\alpha$-tocopherol and absolute concentrations of vitamin D and retinol were not affected by plant sterol and plant stanol consumption. Our data based on 41 studies available in December 2014 are partly in agreement with these earlier findings, since we observed a significant decrease in all TC-standardized hydrocarbon carotenoid concentrations, while Katan et al. only reported a significant decrease in TC-standardized $\beta$-carotene but not in TC-standardized $\alpha$-carotene and lycopene concentrations.

Regarding the interpretation of changes in absolute fatsoluble vitamin and carotenoid concentrations, it needs to be emphasized that these components are transported by lipoproteins (except retinol and vitamin D) [60, 61]. Therefore, a reduction in non-standardized concentrations might be the result of reduced carrier capacity, as evidenced by lower serum cholesterol concentrations after plant sterol or plant stanol intake. For this reason, fat-soluble vitamin and carotenoid concentrations are generally standardized for various plasma lipid fractions. We chose to standardize for TC (reflecting cholesterol in all lipoproteins), since fatsoluble vitamins and carotenoids are not selectively carried 
in one lipoprotein fraction. After standardization for TC, $\alpha$ and $\gamma$-tocopherol concentrations were not changed, while changes in oxygenated carotenoids became less significant (zeaxanthin and $\beta$-cryptoxanthin) or were no longer present (lutein). Reductions in TC-standardized concentrations for all hydrocarbon carotenoids ( $\beta$-carotene, $\alpha$-carotene and lycopene) remained significant although relative changes were smaller compared with the non-standardized changes. This suggests that reductions in non-standardized tocopherol concentrations can primarily be explained by a reduction in the number of lipoprotein particles, while changes in non-standardized carotenoid concentrations can only partly be explained by a decrease in carrier capacity. For the lipophilic hydrocarbon carotenoids, other factors should be considered to explain the observed reductions. Analog to cholesterol, plant sterol and plant stanols, fat-soluble vitamins and carotenoids are lipophilic compounds that require solubilization into mixed micelles for intestinal absorption [60, 61]. Plant sterols and plant stanols interfere with micellar sterol composition and probably also interact with incorporation of fat-soluble vitamins and carotenoids in the micelles. This seems particularly evident for the more lipophilic hydrocarbon carotenoids for which the largest reductions in serum concentrations were found after plant sterol or plant stanol intake. Indeed, Plat and Mensink [19] have shown that changes in hydrocarbon (but not in oxygenated) carotenoid concentrations were significantly related to reductions in markers of cholesterol absorption after plant stanol consumption.

Subgroup analyses showed a stronger reduction in relative TC-standardized $\beta$-carotene concentrations and a trend toward larger reductions in TC-standardized $\alpha$-tocopherol concentrations after plant stanol consumption as compared with plant sterol consumption. Changes in TC concentrations were also larger after consumption of plant stanols compared with plant sterols. Plant stanol studies investigated overall higher doses $(3.2$ vs. $2.1 \mathrm{~g} / \mathrm{d}$ with plant sterols), which probably explains the larger TC-lowering efficacy. Indeed, subgroup analyses indicated that TC concentrations decreased dose dependently. Even though a dose-response effect was lacking for relative TC-standardized $\beta$-carotene concentrations, largest decreases were seen in the highest dose category $(3.0<$ dose $\leq 9.0 \mathrm{~g} / \mathrm{d})$. As plant stanol studies investigated overall higher doses, the difference between plant sterol and stanol studies on relative TCstandardized $\beta$-carotene concentrations might be explained by a difference in average dose. Nevertheless, this is still an unexpected finding and a side-by-side comparison would be needed to evaluate a difference between plant sterols and plant stanols on serum $\beta$-carotene concentrations in more detail. Baseline concentrations as well as the duration of the interventions did not have a major impact on plasma fat-soluble vitamin and carotenoid concentrations after plant sterol or plant stanol consumption. In addition, as already mentioned, a clear dose-response effect was lacking for fat-soluble vitamin and carotenoid concentrations, while TC concentrations decreased dose dependently after plant sterol or plant stanol consumption. Such a dose-dependent cholesterol lowering has been shown by Mensink et al. [16], where a linear dose-response relationship was reported for plant stanol intake and cholesterol decrease up to $9 \mathrm{~g} / \mathrm{d}$. A dose-response relationship for the reduction in LDL-C at least up to intakes of $3 \mathrm{~g} / \mathrm{d}$ of plant sterols and stanols was also found in the meta-analysis of Ras et al. [3].

Whether the observed reductions in plasma tocopherols and especially carotenoid concentrations are clinically relevant is not known. In fact, ranges of plasma fat-soluble vitamin and carotenoid concentrations that are defined as normal are very wide $[62,63]$. The Food and Nutrition Board of the Health and Medicine Division reported, based on data of more than 20.000 subjects who participated in the NHANES 1988-1994 [64], an average plasma $\beta$-carotene concentration of $0.35 \mu \mathrm{mol} / \mathrm{L}$, and $95 \%$ of the subjects had values between 0.10 and $0.86 \mu \mathrm{mol} / \mathrm{L}$. We observed that $\beta$-carotene was reduced from $0.60 \mu \mathrm{mol} / \mathrm{L}$ (95\% CI $0.54 ; 0.67)$ to $0.52 \mu \mathrm{mol} / \mathrm{L}$ (95\% CI $0.46 ; 0.57)$ after plant sterol and plant stanol consumption; thus, $\beta$-carotene concentrations remained within normal ranges. In addition, they reported [64] average concentrations of $\alpha$-carotene $0.09(0.02-0.23) \mu \mathrm{mol} / \mathrm{L}, \beta$-cryptoxanthin $0.17(0.06-0.36) \mu \mathrm{mol} / \mathrm{L}$ and lycopene $0.44(0.18-0.76)$ $\mu \mathrm{mol} / \mathrm{L}$. Lutein and zeaxanthin were reported together with an average concentration of $0.37(0.17-0.68) \mu \mathrm{mol} / \mathrm{L}$. Our observed carotenoid concentrations remained within these reported ranges after plant sterol and plant stanol consumption. Ford et al. [65] reported a mean $\alpha$-tocopherol concentration of $27.4(95 \%$ CI $26.7 ; 28.1) \mu \mathrm{mol} / \mathrm{L}$ and a mean $\gamma$-tocopherol concentration of 4.8 (95\% CI 4.5; 5.1) $\mu \mathrm{mol} / \mathrm{L}$ in $>4000$ subjects who participated in NHANES 1999-2000. We observed overall higher $\alpha$-tocopherol concentrations and lower $\gamma$-tocopherol concentrations, which can be explained by a higher intake of $\gamma$-tocopherol in the US diet compared to a higher $\alpha$-tocopherol intake in the European diet. Nevertheless, our observed total tocopherol concentration ( $\alpha$ - and $\gamma$-tocopherol) after plant sterol and stanol intake remained within ranges as presented for 450 healthy subjects [63] with a median value of 28.6 (18.446.0) $\mu \mathrm{mol} / \mathrm{L}$ and $>20.000$ subjects who participated in NHANES 1988-1994 with a mean concentration of 25.3 (14.6-43.6) $\mu \mathrm{mol} / \mathrm{L}[64]$.

For CVD, the overall notion is that a healthy diet with high intakes of fruit and vegetables may lower the risk to develop CVD. Whether this effect is related to antioxidants is not known, also because clinical trials do not support a causal role for antioxidant supplementation in the 
prevention of chronic diseases such as CVD $[8,9]$. In contrast, some prospective cohort studies have reported inverse associations between absolute carotenoid concentrations and the risk to develop CVD or cancers [5, 7, 66], although such relationships have not been observed in all studies [67, 68]. In addition, associations do not imply causality, complicating the interpretation of decreased plasma carotenoid concentrations after plant sterol or stanol consumption. Except for a possible role as antioxidant, it is well established that carotenoids (particularly $\beta$-carotene) are a precursor for the synthesis of vitamin A [69]. However, serum vitamin A (retinol) concentrations were not changed after plant sterol or plant stanol intake. A more consistent association is present for dietary lutein and zeaxanthin intake, where higher plasma concentrations are associated with a reduced risk to develop advanced AMD [6]. Although data are limited, active modulation of plasma lutein concentrations by supplementation may also affect AMD and CVD risk [70, 71].

The reported changes in fat-soluble vitamins and carotenoids should also be placed in context of other (dietary) interventions where intestinal absorption of nutrients or carrier capacity in plasma is potentially affected. The addition of dietary fibers such as oat and barley $\beta$-glucans to the diet reduces serum cholesterol concentrations [72, 73] but have also been reported to affect fat-soluble vitamin and carotenoid concentrations in humans [74, 75]. Moreover, Kerckhoffs [76] showed a reduction of $7.2 \%(P<0.05)$ in lipid-standardized hydrocarbon carotenoid concentrations after consumption of $5 \mathrm{~g} / \mathrm{d}$ of oat $\beta$-glucan for 2 weeks in 25 healthy subjects. In six healthy women, adding wheat bran to an antioxidant mixture reduced the postprandial response of lycopene and lutein concentrations, while pectin, guar and alginate (water-soluble fibers) reduced $\beta$-carotene, lycopene and lutein concentrations [77]. The postprandial response of $\alpha$-tocopherol was not changed after consumption of these dietary fibers, which probably relates to the lower lipophilicity of $\alpha$-tocopherol [77]. Besides cholesterol-lowering foods, pharmacological intervention aimed to reduce serum cholesterol concentrations might also have an effect on fatsoluble vitamin and carotenoid concentrations. HMG-CoA reductases inhibitors (statins) are the most frequently prescribed cholesterol-lowering drugs worldwide, and reductions up to $50 \%$ can be achieved with statin therapy [78]. However, despite their effects on serum cholesterol concentrations, concentrations of fat-soluble vitamin and carotenoid are not reduced. If anything, lipoprotein particles become enriched in vitamin/carotenoids after statin therapy [76, 79, 80]. Another cholesterol-lowering drug is ezetimibe, which reduces intestinal uptake of cholesterol by acting on the intestinal cholesterol transporter NPC1L1 [81]. Ezetimbe is a relatively new approach to lower cholesterol concentrations and human data describing whether ezetimibe therapy has an effect on fat-soluble vitamin and carotenoid concentrations is lacking. There are, however, some indications from in vitro studies that ezetimibe affects the intestinal transport of carotenoids and that this effect decreases with increasing polarity of the carotenoids [82]. Other compounds that interfere with cholesterol absorption (i.e., neomycin), fat absorption (olestra) and bile acid reabsorption (cholestyramine) have also been shown to reduce tocopherol and carotenoid concentrations. Reported effects were at least as large or larger than observed for plant sterols or stanols [83-85].

The question is whether the observed changes in plasma fat-soluble vitamins and carotenoids during consumption of plant sterol or stanol ester-enriched foods can be corrected for? It has been indeed reported that reductions in plasma carotenoid concentrations can be prevented by adopting a healthy diet with at least five servings per day of vegetables and/or fruit as recommend by many guidelines for a healthy $\operatorname{diet}[48,86]$. For instance, the recently released AHA/ACC lifestyle management guidelines for healthy living emphasize the consumption of vegetables, fruits and whole grains for adults who wish to lower their LDL-C concentrations [87]. Other guidelines like the one of the ESC/EAS also mention the consumption of plant sterol- and plant stanolenriched foods in order to further enhance the cholesterollowering effect of a healthy diet [88]. Finally, consumption of a cholesterol-lowering dietary portfolio, which was rich in plant sterols, viscous fibers, soy proteins and nuts for 6 months, reduced LDL-C concentrations $(-13.1 \%$, CI -16.7 to $-9.5 \%$ ) without affecting TC-standardized tocopherol and carotenoid concentrations [89]. Again, this demonstrates that it is possible to counteract a decrease in TC-standardized carotenoid concentrations after consumption of plant sterol and plant stanol-enriched foods by changing to a recommended dietary pattern.

The current meta-analysis included study evidence based on a variety of experimental study designs regarding aspects such as duration of intervention, food products used and different population groups, which could have contributed to the observed heterogeneity between the studies. However, heterogeneity was only present in a few measured parameters with relative small $\mathrm{I}^{2}$ statistics, suggesting little variability between the included studies. In addition, we here report comparable changes in serum cholesterol and lipoprotein concentrations as found in previously published meta-analyses [1-3], implying that the included studies in this meta-analyses are representative of all available studies in the literature that have been performed with plant sterols and plant stanols.

In summary, this meta-analysis including data of 41 RCTs showed that consumption of plant sterols and plant stanols reduces TC-standardized hydrocarbon carotenoid concentrations ( $\beta$-carotene, $\alpha$-carotene and lycopene), differently affects TC-standardized oxygenated 
carotenoid concentrations (reduction in zeaxanthin and $\beta$-cryptoxanthin but not in lutein) and does not affect TCstandardized tocopherol concentrations or absolute retinol and vitamin D concentrations. Observed levels in this meta-analysis remained within ranges that are considered to be normal and there are no strong indications that the observed decreases have negative health implications.

Acknowledgments RTR and EAT are employed by Unilever R\&D. Unilever markets food products with added plant sterols. This research was supported by a restricted grant from Unilever R\&D for the realization of this systematic review and meta-analysis.

Authors' contributions The authors' responsibilities were as follows: SB, RTR, EAT, RPM and JP designed the research; SB and RTR conducted the research, analyzed the data and performed the statistical analysis; SB, RTR, EAT, RPM and JP wrote the manuscript and JP had primary responsibility for the final content of the manuscript. All authors approved the final manuscript.

\section{Compliance with ethical standards}

Conflict of interest SB, RPM and JP have no conflicts of interest to declare.

Open Access This article is distributed under the terms of the Creative Commons Attribution 4.0 International License (http://creativecommons.org/licenses/by/4.0/), which permits unrestricted use, distribution, and reproduction in any medium, provided you give appropriate credit to the original author(s) and the source, provide a link to the Creative Commons license, and indicate if changes were made.

\section{References}

1. Abumweis SS, Barake R, Jones PJ (2008) Plant sterols/stanols as cholesterol lowering agents: a meta-analysis of randomized controlled trials. Food Nutr Res 52. doi:10.3402/fnr.v52i0.1811

2. Demonty I, Ras RT, van der Knaap HC, Duchateau GS, Meijer L, Zock PL, Geleijnse JM, Trautwein EA (2009) Continuous dose-response relationship of the LDL-cholesterol-lowering effect of phytosterol intake. J Nutr 139(2):271-284. doi:10.3945/ jn. 108.095125

3. Ras RT, Geleijnse JM, Trautwein EA (2014) LDL-cholesterollowering effect of plant sterols and stanols across different dose ranges: a meta-analysis of randomised controlled studies. Br J Nutr 112(2):214-219. doi:10.1017/S0007114514000750

4. De Smet E, Mensink RP, Plat J (2012) Effects of plant sterols and stanols on intestinal cholesterol metabolism: suggested mechanisms from past to present. Mol Nutr Food Res 56(7):1058-1072. doi:10.1002/mnfr.201100722

5. Bakker MF, Peeters PH, Klaasen VM, Bueno-de-Mesquita HB, Jansen EH, Ros MM, Travier N, Olsen A, Tjonneland A, Overvad $\mathrm{K}$ et al (2016) Plasma carotenoids, vitamin C, tocopherols, and retinol and the risk of breast cancer in the European Prospective Investigation into Cancer and Nutrition cohort. Am J Clin Nutr 103(2):454-464. doi:10.3945/ajcn.114.101659

6. Wu J, Cho E, Willett WC, Sastry SM, Schaumberg DA (2015) Intakes of lutein, zeaxanthin, and other carotenoids and agerelated macular degeneration during 2 decades of prospective follow-up. JAMA Ophthalmol 133(12):1415-1424. doi:10.1001/ jamaophthalmol.2015.3590

7. Morris DL, Kritchevsky SB, Davis CE (1994) Serum carotenoids and coronary heart disease. The lipid research clinics coronary primary prevention trial and follow-up study. JAMA 272(18):1439-1441

8. Hennekens CH, Buring JE, Manson JE, Stampfer M, Rosner B, Cook NR, Belanger C, LaMotte F, Gaziano JM, Ridker PM et al (1996) Lack of effect of long-term supplementation with beta carotene on the incidence of malignant neoplasms and cardiovascular disease. N Engl J Med 334(18):1145-1149. doi:10.1056/ NEJM199605023341801

9. Omenn GS, Goodman GE, Thornquist MD, Balmes J, Cullen MR, Glass A, Keogh JP, Meyskens FL, Valanis B, Williams JH et al (1996) Effects of a combination of beta carotene and vitamin A on lung cancer and cardiovascular disease. N Engl J Med 334(18):1150-1155. doi:10.1056/NEJM199605023341802

10. Katan MB, Grundy SM, Jones P, Law M, Miettinen T, Paoletti R, Stresa Workshop P (2003) Efficacy and safety of plant stanols and sterols in the management of blood cholesterol levels. Mayo Clin Proc 78(8):965-978. doi:10.4065/78.8.965

11. Plat J, Mensink RP (2001) Effects of diets enriched with two different plant stanol ester mixtures on plasma ubiquinol-10 and fat-soluble antioxidant concentrations. Metabolism 50(5):520 529. doi:10.1053/meta.2001.22509

12. Fardet A, Morise A, Kalonji E, Margaritis I, Mariotti F (2015) Influence of phytosterol and phytostanol food supplementation on plasma liposoluble vitamins and provitamin A carotenoid levels in humans: An updated review of the evidence. Crit Rev Food Sci Nutr: 0. doi:10.1080/10408398.2015.1033611

13. Sierksma A, Weststrate JA, Meijer GW (1999) Spreads enriched with plant sterols, either esterified 4,4-dimethylsterols or free 4-desmethylsterols, and plasma total- and LDL-cholesterol concentrations. Br J Nutr 82(4):273-282

14. Weststrate JA, Meijer GW (1998) Plant sterol-enriched margarines and reduction of plasma total- and LDL-cholesterol concentrations in normocholesterolaemic and mildly hypercholesterolaemic subjects. Eur J Clin Nutr 52(5):334-343

15. Maki KC, Davidson MH, Umporowicz DM, Schaefer EJ, Dicklin MR, Ingram KA, Chen S, McNamara JR, Gebhart BW, RibayaMercado JD et al (2001) Lipid responses to plant-sterol-enriched reduced-fat spreads incorporated into a National Cholesterol Education Program Step I diet. Am J Clin Nutr 74(1):33-43

16. Mensink RP, De Jong A, Lutjohann D, Haenen GRMM, Plat J (2010) Plant stanols dose-dependently decrease LDL-cholesterol concentrations, but not cholesterol-standardized fat-soluble antioxidant concentrations, at intakes up to $9 \mathrm{~g} / \mathrm{d}$. Am J Clin Nutr 92(1):24-33

17. Mensink RP, Ebbing S, Lindhout M, Plat J, Van Heugten MMA (2002) Effects of plant stanol esters supplied in low-fat yoghurt on serum lipids and lipoproteins, non-cholesterol sterols and fat soluble antioxidant concentrations. Atherosclerosis 160(1):205-213

18. Noakes M, Clifton PM, Doornbos AME, Trautwein EA (2005) Plant sterol ester-enriched milk and yoghurt effectively reduce serum cholesterol in modestly hypercholesterolemic subjects. Eur J Nutr 44(4):214-222

19. Plat J, Mensink RP (2001) Effects of diets enriched with two different plant stanol ester mixtures on plasma ubiquinol-10 and fat-soluble antioxidant concentrations. Metab Clin Exp 50(5):520-529

20. Chen SC, Judd JT, Kramer M, Meijer GW, Clevidence BA, Baer DJ (2009) Phytosterol intake and dietary fat reduction are independent and additive in their ability to reduce plasma LDL cholesterol. Lipids 44(3):273-281. doi:10.1007/s11745-008-3278-y

21. Homma Y, Ikeda I, Ishikawa T, Tateno M, Sugano M, Nakamura H (2003) Decrease in plasma low-density lipoprotein cholesterol, 
apolipoprotein B, cholesteryl ester transfer protein, and oxidized low-density lipoprotein by plant stanol ester-containing spread: a randomized, placebo-controlled trial. Nutrition 19(4):369-374

22. Mannarino E, Pirro M, Cortese C, Lupattelli G, Siepi D, Mezzetti A, Bertolini S, Parillo M, Fellin R, Pujia A et al (2009) Effects of a phytosterol-enriched dairy product on lipids, sterols and 8-isoprostane in hypercholesterolemic patients: a multicenter Italian study. Nutr Metab Cardiovasc Dis 19(2):84-90. doi:10.1016/j.numecd.2008.03.012

23. Nguyen TT, Dale LC, von Bergmann K, Croghan IT (1999) Cholesterol-lowering effect of stanol ester in a US population of mildly hypercholesterolemic men and women: a randomized controlled trial. Mayo Clin Proc 74(12):1198-1206

24. Seki S, Abe T, Hidaka I, Kojika K, Yoshino H, Aoyama T, Okazaki M, Kondo K (2003) Effects of phytosterol ester-enriched vegetable oil on serum cholesterol and assessment of safety in healthy men. J Oleo Sci 52(4):205-213

25. Seki S, Hidaka I, Kojima K, Yoshino H, Aoyama T, Okazaki M, Kondo K (2003) Effects of phytosterol ester-enriched vegetable oil on plasma lipoproteins in healthy men. Asia Pac J Clin Nutr 12(3):282-291

26. Davidson MH, Maki KC, Umporowicz DM, Ingram KA, Dicklin MR, Schaefer E, Lane RW, McNamara JR, Ribaya-Mercado JD, Perrone G et al (2001) Safety and tolerability of esterified phytosterols administered in reduced-fat spread and salad dressing to healthy adult men and women. J Am Coll Nutr 20(4):307-319

27. Wan X, Wang W, Liu J, Tong T (2014) Estimating the sample mean and standard deviation from the sample size, median, range and/or interquartile range. BMC Med Res Methodol 14:135. doi:10.1186/1471-2288-14-135

28. Christiansen LI, Lahteenmaki PL, Mannelin MR, SeppanenLaakso TE, Hiltunen RV, Yliruusi JK (2001) Cholesterol-lowering effect of spreads enriched with microcrystalline plant sterols in hypercholesterolemic subjects. Eur J Nutr 40(2):66-73

29. Hendriks HF, Brink EJ, Meijer GW, Princen HM, Ntanios FY (2003) Safety of long-term consumption of plant sterol estersenriched spread. Eur J Clin Nutr 57(5):681-692. doi:10.1038/ sj.ejen. 1601598

30. Hernandez-Mijares A, Banuls C, Rocha M, Morillas C, MartinezTriguero ML, Victor VM, Lacomba R, Alegria A, Barbera R, Farre $\mathrm{R}$ et al (2010) Effects of phytosterol ester-enriched low-fat milk on serum lipoprotein profile in mildly hypercholesterolaemic patients are not related to dietary cholesterol or saturated fat intake. Br J Nutr 104(7):1018-1025. doi:10.1017/S0007114510001686

31. Korpela R, Tuomilehto J, Hogstrom P, Seppo L, Piironen V, Salo-Vaananen P, Toivo J, Lamberg-Allardt C, Karkkainen M, Outila $\mathrm{T}$ et al (2006) Safety aspects and cholesterol-lowering efficacy of low fat dairy products containing plant sterols. Eur J Clin Nutr 60(5):633-642. doi:10.1038/sj.ejen.1602362

32. Higgins JPT, Green S (eds) (2011) Cochrane handbook for systematic reviews of interventions version 5.1.0 [updated March 2011]. The Cochrane Collaboration

33. Friedewald WT, Levy RI, Fredrickson DS (1972) Estimation of the concentration of low-density lipoprotein cholesterol in plasma, without use of the preparative ultracentrifuge. Clin Chem 18(6):499-502

34. Carr TP, Krogstrand KL, Schlegel VL, Fernandez ML (2009) Stearate-enriched plant sterol esters lower serum LDL cholesterol concentration in normo- and hypercholesterolemic adults. $\mathrm{J}$ Nutr 139(8):1445-1450. doi:10.3945/jn.109.106328

35. DerSimonian R, Laird N (1986) Meta-analysis in clinical trials. Control Clin Trials 7(3):177-188

36. Higgins JP, Thompson SG (2002) Quantifying heterogeneity in a meta-analysis. Stat Med 21(11):1539-1558. doi:10.1002/sim.1186
37. Egger M, Davey Smith G, Schneider M, Minder C (1997) Bias in meta-analysis detected by a simple, graphical test. BMJ 315(7109):629-634

38. Devaraj S, Autret BC, Jialal I (2006) Reduced-calorie orange juice beverage with plant sterols lowers C-reactive protein concentrations and improves the lipid profile in human volunteers. Am J Clin Nutr 84(4):756-761

39. Gylling H, Hallikainen M, Nissinen MJ, Miettinen TA (2010) The effect of a very high daily plant stanol ester intake on serum lipids, carotenoids, and fat-soluble vitamins. Clin Nutr 29(1):112-118. doi:10.1016/j.clnu.2009.08.005

40. Hallikainen MA, Sarkkinen ES, Uusitupa MI (1999) Effects of low-fat stanol ester enriched margarines on concentrations of serum carotenoids in subjects with elevated serum cholesterol concentrations. Eur J Clin Nutr 53(12):966-969

41. Hansel B, Nicolle C, Lalanne F, Tondu F, Lassel T, Donazzolo Y, Ferrieres J, Krempf M, Schlienger JL, Verges B et al (2007) Effect of low-fat, fermented milk enriched with plant sterols on serum lipid profile and oxidative stress in moderate hypercholesterolemia. Am J Clin Nutr 86(3):790-796

42. Kriengsinyos W, Sumriddetchkajorn K, Yamborisut U (2011) Reduction of LDL-cholesterol in mildly hypercholesterolemic Thais with plant stanol ester-fortified soy milk. J Med Assoc Thai 94(11):1327-1336

43. Masuda O, Higuchi T (2007) Drink containing plant sterols improves the serum cholesterol in human with mild hypercholesterolemia. Japanese Pharmacol Ther 35:989-1003

44. Masuda O, Higuchi T, Tsuzuku T, Ohashi Y, Sato K, Inoguchi M, Wataru S, Nakamura K (2007) Safety evaluation of excessive intake of the drink containing plant sterol in subjects with normocholesterolemic and mildly hypercholesterolemic. Japanese Pharmacol Ther 35(9):963-971

45. Matsuoka R, Masuda Y, Takeuchi A, Marushima R, Hasegawa M, Sakamoto A, Hirata H, Kajimoto O, Homma Y (2004) A double-blind, placebo-controlled study on the effects of mayonnaise containing free plant sterol on serum cholesterol concentration; safety evaluation for normocholesterolemic and mildly hypercholesterolemic Japanese subjects. J Oleo Sci 53(2):79-88

46. Amundsen AL, Ose L, Nenseter MS, Ntanios FY (2002) Plant sterol ester-enriched spread lowers plasma total and LDL cholesterol in children with familial hypercholesterolemia. Am J Clin Nutr 76(2):338-344

47. Clifton PM, Noakes M, Sullivan D, Erichsen N, Ross D, Annison G, Fassoulakis A, Cehun M, Nestel P (2004) Cholesterollowering effects of plant sterol esters differ in milk, yoghurt, bread and cereal. Eur J Clin Nutr 58(3):503-509. doi:10.1038/ sj.ejcn. 1601837

48. Colgan HA, Floyd S, Noone EJ, Gibney MJ, Roche HM (2004) Increased intake of fruit and vegetables and a low-fat diet, with and without low-fat plant sterol-enriched spread consumption: effects on plasma lipoprotein and carotenoid metabolism. J Hum Nutr Diet 17(6):561-569; quiz 571-564. doi:10.1111/j.1365-277X.2004.00564.x

49. Gylling H, Miettinen TA (1999) Cholesterol reduction by different plant stanol mixtures and with variable fat intake. Metabolism 48(5):575-580

50. Hallikainen MA, Sarkkinen ES, Gylling H, Erkkila AT, Uusitupa MI (2000) Comparison of the effects of plant sterol ester and plant stanol ester-enriched margarines in lowering serum cholesterol concentrations in hypercholesterolaemic subjects on a lowfat diet. Eur J Clin Nutr 54(9):715-725

51. Hallikainen MA, Sarkkinen ES, Uusitupa MI (2000) Plant stanol esters affect serum cholesterol concentrations of hypercholesterolemic men and women in a dose-dependent manner. J Nutr 130(4):767-776 
52. Heggen E, Granlund L, Pedersen JI, Holme I, Ceglarek U, Thiery J, Kirkhus B, Tonstad S (2010) Plant sterols from rapeseed and tall oils: effects on lipids, fat-soluble vitamins and plant sterol concentrations. Nutr Metab Cardiovasc Dis 20(4):258265. doi:10.1016/j.numecd.2009.04.001

53. Hendriks HF, Weststrate JA, van Vliet T, Meijer GW (1999) Spreads enriched with three different levels of vegetable oil sterols and the degree of cholesterol lowering in normocholesterolaemic and mildly hypercholesterolaemic subjects. Eur J Clin Nutr 53(4):319-327

54. Judd JT, Baer DJ, Chen SC, Clevidence BA, Muesing RA, Kramer M, Meijer GW (2002) Plant sterol esters lower plasma lipids and most carotenoids in mildly hypercholesterolemic adults. Lipids 37(1):33-42

55. Ntanios FY, Homma Y, Ushiro S (2002) A spread enriched with plant sterol-esters lowers blood cholesterol and lipoproteins without affecting vitamins $\mathrm{A}$ and $\mathrm{E}$ in normal and hypercholesterolemic Japanese men and women. J Nutr 132(12):3650-3655

56. Plat J, van Onselen ENM, van Heugten MMA, Mensink RP (2000) Effects on serum lipids, lipoproteins and fat soluble antioxidant concentrations of consumption frequency of margarines and shortenings enriched with plant stanol esters. Eur J Clin Nutr 54(9):671-677

57. Raeini-Sarjaz M, Ntanios FY, Vanstone CA, Jones PJH (2002) No changes in serum fat-soluble vitamin and carotenoid concentrations with the intake of plant sterol/stanol esters in the context of a controlled diet. Metab Clin Exp 51(5):652-656

58. Rudkowska I, AbuMweis SS, Nicolle C, Jones PJH (2008) Cholesterol-lowering efficacy of plant sterols in low-fat yogurt consumed as a snack or with a meal. J Am Coll Nutr 27(5):588-595

59. Thomsen AB, Hansen HB, Christiansen C, Green H, Berger A (2004) Effect of free plant sterols in low-fat milk on serum lipid profile in hypercholesterolemic subjects. Eur J Clin Nutr 58(6):860-870

60. Norum KR, Blomhoff R (1992) McCollum Award Lecture, 1992: vitamin A absorption, transport, cellular uptake, and storage. Am J Clin Nutr 56(4):735-744

61. Parker RS (1996) Absorption, metabolism, and transport of carotenoids. FASEB J 10(5):542-551

62. Greenberg ER, Baron JA, Karagas MR, Stukel TA, Nierenberg DW, Stevens MM, Mandel JS, Haile RW (1996) Mortality associated with low plasma concentration of beta carotene and the effect of oral supplementation. JAMA 275(9):699-703

63. Olmedilla B, Granado F, Gil-Martinez E, Blanco I, RojasHidalgo E (1997) Reference values for retinol, tocopherol, and main carotenoids in serum of control and insulin-dependent diabetic Spanish subjects. Clin Chem 43(6 Pt 1):1066-1071

64. IOM (2000) Dietary reference intakes for Vitamin C, Vitamin E, Selenium and Carotenoids. Institute of Medicine, National Academy Press, 2101 Constitution Avenue, N.W. Washington, DC 20418

65. Ford ES, Schleicher RL, Mokdad AH, Ajani UA, Liu S (2006) Distribution of serum concentrations of alpha-tocopherol and gammatocopherol in the US population. Am J Clin Nutr 84(2):375-383

66. Gann PH, Ma J, Giovannucci E, Willett W, Sacks FM, Hennekens CH, Stampfer MJ (1999) Lower prostate cancer risk in men with elevated plasma lycopene levels: results of a prospective analysis. Cancer Res 59(6):1225-1230

67. Key TJ, Appleby PN, Travis RC, Albanes D, Alberg AJ, Barricarte A, Black A, Boeing H, Bueno-de-Mesquita HB, Chan JM et al (2015) Carotenoids, retinol, tocopherols, and prostate cancer risk: pooled analysis of 15 studies. Am J Clin Nutr 102(5):1142-1157. doi:10.3945/ajcn.115.114306

68. Shardell MD, Alley DE, Hicks GE, El-Kamary SS, Miller RR, Semba RD, Ferrucci L (2011) Low-serum carotenoid concentrations and carotenoid interactions predict mortality in US adults: the Third National Health and Nutrition Examination Survey. Nutr Res 31(3):178-189. doi:10.1016/j.nutres.2011.03.003

69. Sommer A, Vyas KS (2012) A global clinical view on vitamin A and carotenoids. Am J Clin Nutr 96(5):1204S-1206S. doi:10.3945/ajen.112.034868

70. Murray IJ, Makridaki M, van der Veen RL, Carden D, Parry NR, Berendschot TT (2013) Lutein supplementation over a oneyear period in early AMD might have a mild beneficial effect on visual acuity: the CLEAR study. Invest Ophthalmol Vis Sci 54(3):1781-1788. doi:10.1167/iovs.12-10715

71. Zou ZY, Xu XR, Lin XM, Zhang HB, Xiao X, Ouyang L, Huang YM, Wang X, Liu YQ (2014) Effects of lutein and lycopene on carotid intima-media thickness in Chinese subjects with subclinical atherosclerosis: a randomised, double-blind, placebo-controlled trial. Br J Nutr 111(3):474-480. doi:10.1017/ S0007114513002730

72. AbuMweis SS, Jew S, Ames NP (2010) $\beta$-glucan from barley and its lipid-lowering capacity: a meta-analysis of randomized, controlled trials. Eur J Clin Nutr 64(12):1472-1480. doi:10.1038/ ejcn.2010.178

73. Whitehead A, Beck EJ, Tosh S, Wolever TM (2014) Cholesterollowering effects of oat beta-glucan: a meta-analysis of randomized controlled trials. Am J Clin Nutr 100(6):1413-1421. doi:10.3945/ajen.114.086108

74. Palafox-Carlos H, Ayala-Zavala JF, Gonzalez-Aguilar GA (2011) The role of dietary fiber in the bioaccessibility and bioavailability of fruit and vegetable antioxidants. J Food Sci 76(1):R6-R15. doi:10.1111/j.1750-3841.2010.01957.x

75. van Het Hof KH, West CE, Weststrate JA, Hautvast JG (2000) Dietary factors that affect the bioavailability of carotenoids. J Nutr 130(3):503-506

76. Kerckhoffs DAJM (2003) Dietary components and cardiovascular risk markers: effects of tocotrienols, b-glucan and plant stanol esters. Chapter 5: the effects of plant stanol esters, oat b-glucan and pravastatin on plasma lipid-solible antioxidants in subjects with increased serum cholesterol concentrations. $\mathrm{PhD}$ thesis, Maastricht University. ISBN 90-9016633-5

77. Riedl J, Linseisen J, Hoffmann J, Wolfram G (1999) Some dietary fibers reduce the absorption of carotenoids in women. J Nutr 129(12):2170-2176

78. Cholesterol Treatment Trialists C, Baigent C, Blackwell L, Emberson J, Holland LE, Reith C, Bhala N, Peto R, Barnes EH, Keech A et al. (2010) Efficacy and safety of more intensive lowering of LDL cholesterol: a meta-analysis of data from 170,000 participants in 26 randomised trials. Lancet 376(9753):1670 1681. doi:10.1016/S0140-6736(10)61350-5

79. Ryden M, Leanderson P, Kastbom KO, Jonasson L (2012) Effects of simvastatin on carotenoid status in plasma. Nutr Metab Cardiovasc Dis 22(1):66-71. doi:10.1016/j.numecd.2010.04.009

80. Sahebkar A, Simental-Mendia LE, Ferretti G, Bacchetti T, Golledge J (2015) Statin therapy and plasma vitamin E concentrations: a systematic review and meta-analysis of randomized placebo-controlled trials. Atherosclerosis 243(2):579-588. doi:10.1016/j.atherosclerosis.2015.09.028

81. Garcia-Calvo M, Lisnock J, Bull HG, Hawes BE, Burnett DA, Braun MP, Crona JH, Davis HR Jr, Dean DC, Detmers PA et al (2005) The target of ezetimibe is Niemann-Pick C1-Like 1 (NPC1L1). Proc Natl Acad Sci USA 102(23):8132-8137. doi:10.1073/pnas.0500269102

82. During A, Dawson HD, Harrison EH (2005) Carotenoid transport is decreased and expression of the lipid transporters SR-BI, NPC1L1, and ABCA1 is downregulated in Caco-2 cells treated with ezetimibe. J Nutr 135(10):2305-2312

83. Ayres EJ, Hoeg JM, Bailey KR, Bieri JG (1986) The effect of neomycin on plasma alpha tocopherol levels in type II hyperlipoproteinemia. Drug Nutr Interact 4(4):325-331 
84. Elinder LS, Hadell K, Johansson J, Molgaard J, Holme I, Olsson AG, Walldius G (1995) Probucol treatment decreases serum concentrations of diet-derived antioxidants. Arterioscler Thromb Vasc Biol 15(8): 1057-1063

85. Koonsvitsky BP, Berry DA, Jones MB, Lin PY, Cooper DA, Jones DY, Jackson JE (1997) Olestra affects serum concentrations of alpha-tocopherol and carotenoids but not vitamin $\mathrm{D}$ or vitamin $\mathrm{K}$ status in free-living subjects. J Nutr $127(8$ Suppl):1636S-1645S

86. Noakes M, Clifton P, Ntanios F, Shrapnel W, Record I, McInerney $\mathbf{J}$ (2002) An increase in dietary carotenoids when consuming plant sterols or stanols is effective in maintaining plasma carotenoid concentrations. Am J Clin Nutr 75(1):79-86

87. Eckel RH, Jakicic JM, Ard JD, de Jesus JM, Houston Miller N, Hubbard VS, Lee IM, Lichtenstein AH, Loria CM, Millen BE et al (2014) 2013 AHA/ACC guideline on lifestyle management to reduce cardiovascular risk: a report of the American College of Cardiology/American Heart Association Task Force on
Practice Guidelines. J Am Coll Cardiol 63(25 Pt B):2960-2984. doi:10.1016/j.jacc.2013.11.003

88. European Association for Cardiovascular P, Rehabilitation, Reiner Z, Catapano AL, De Backer G, Graham I, Taskinen MR, Wiklund O, Agewall S, Alegria E et al. (2011) ESC/EAS guidelines for the management of dyslipidaemias: the task force for the management of dyslipidaemias of the European Society of Cardiology (ESC) and the European Atherosclerosis Society (EAS). Eur Heart J 32(14):1769-1818. doi:10.1093/eurheartj/ ehr158

89. Ramprasath VR, Jenkins DJ, Lamarche B, Kendall CW, Faulkner D, Cermakova L, Couture P, Ireland C, Abdulnour S, Patel D et al (2014) Consumption of a dietary portfolio of cholesterol lowering foods improves blood lipids without affecting concentrations of fat soluble compounds. Nutr J 13:101. doi:10.1186/1475-2891-13-101 